\title{
Frontiers in Biological Catalysis
}

Biochemical Society Annual Symposium No. 79 held at Robinson College, Cambridge, U.K., 10-12 January 2012. Organized and Edited by David Leys (Manchester, U.K.), Andrew Munro (Manchester, U.K.), Emma Raven (Leicester, U.K.) and Martin Warren (University of Kent, U.K.).

\section{Exploring the biochemistry at the extracellular redox frontier of bacterial mineral Fe(III) respiration}

\author{
David J. Richardson*1, Marcus J. Edwards", Gaye F. White*, Nanakow Baiden*, Robert S. Hartshorne*, \\ Jim Fredricksont, Liang Shi†, John Zachara†, Andrew J. Gates", Julea N. Butt* and Thomas A. Clarke* \\ "Centre for Molecular and Structural Biochemistry, School of Biological Sciences, University of East Anglia, Norwich Research Park, Norwich NR4 7TJ, U.K., and \\ $\dagger$ Pacific Northwest National Laboratory, P.O. Box 999, Richland, WA 99352, U.S.A.
}

\begin{abstract}
Many species of the bacterial Shewanella genus are notable for their ability to respire in anoxic environments utilizing insoluble minerals of $\mathrm{Fe}(\mathrm{III})$ and $\mathrm{Mn}$ (IV) as extracellular electron acceptors. In Shewanella oneidensis, the process is dependent on the decahaem electron-transport proteins that lie at the extracellular face of the outer membrane where they can contact the insoluble mineral substrates. These extracellular proteins are charged with electrons provided by an inter-membrane electron-transfer pathway that links the extracellular face of the outer membrane with the inner cytoplasmic membrane and thereby intracellular electron sources. In the present paper, we consider the common structural features of two of these outer-membrane decahaem cytochromes, MtrC and MtrF, and bring this together with biochemical, spectroscopic and voltammetric data to identify common and distinct properties of these prototypical members of different clades of the outer-membrane decahaem cytochrome superfamily.
\end{abstract}

\section{Introduction}

Shewanella oneidensis MR-1 is a Gram-negative facultative anaerobic bacterium that can utilize extracellular mineral metal oxides of $\mathrm{Fe}(\mathrm{III})$ and $\mathrm{Mn}(\mathrm{IV})$ as respiratory electron acceptors [1]. The process of mineral oxide respiration in the Earth's anoxic subsurfaces can be a major driver of organic carbon oxidation and can influence a number of biogeochemical cycles, such as the nitrogen and sulfur cycles. Metal oxide respiration may also contribute to rock weathering and corrosion of subsurface pipeline infrastructure, and might be exploited for bioremediation of subsurface environments polluted by organic contaminants or radionuclides. Metal-oxide-respiring bacteria may also have potential for exploitation in microbial fuel cells in which the anode effectively serves as the extracellular respiratory substrate.

Mineral metal oxides are unable to enter the bacterial cell in an analogous manner to soluble terminal electron acceptors

Key words: cytochrome c, electron paramagnetic resonance (EPR), electron transfer, iron respiration, protein film voltammetry, Shewanello.

Abbreviations used: AMS; 4-acetamido-4'-maleimidylstilbene-2,2'-disulfonic acid; DTT, dithiothreitol; LGM, large $g_{\max }$ MQ, oxidized menaquinone; $\mathrm{MQH}_{2}$, reduced menaquinone; OMDC outer-membrane decahaem cytochrome; PFV, protein film voltammetry; SHE, standard hydrogen electrode; TS2, Type 2 secretion.

${ }^{1}$ To whom correspondence should be addressed (email d.richardson@uea.ac.uk). such as oxygen, nitrite or sulfate. Specific respiratory electron-transfer mechanisms are therefore required to overcome the physical limitations associated with electron transfer to these insoluble extracellular electron acceptors. This requires that electrons are moved from inside the cell to the extracellular frontier, the 'microbe-mineral interface'. In S. oneidensis, this process is dependent on cell-surface $\sim 70$ $85 \mathrm{kDa}$ OMDCs (outer-membrane decahaem cytochromes) $\mathrm{MtrC}, \mathrm{OmcA}$ and MtrF, which receive electrons from a multihaem electron-transport system that wires the periplasm, via an outer-membrane porin, to the extracellular environment $[2,3]$ (Figure 1). MtrC can receive electrons from a smaller $(\sim 35 \mathrm{kDa})$ decahaem cytochrome MtrA that is proposed to extend from the periplasm into the outer membrane by penetrating an outer-membrane porin MtrB [3]. A similar complex is thought to be formed by MtrD, MtrE and MtrF, the synthesis of which is more prevalent in aggregated, rather than planktonic, cells [4]. MtrC and OmcA can also exchange electrons with each other, and only mutant strains deficient in both MtrC and OmcA display a serious deficiency in the reduction of extracellular electron acceptors $[2,5,6]$. Furthermore, engineered complexes can be generated in which MtrF can substitute for MtrC in a MtrABF complex [7]. 
Figure 1 | Cartoon showing the proposed cellular location of the OMDCs and their integration with the respiratory electron-transport system

$\mathrm{Q}$, oxidized quinone; $\mathrm{QH}_{2}$, reduced quinone.

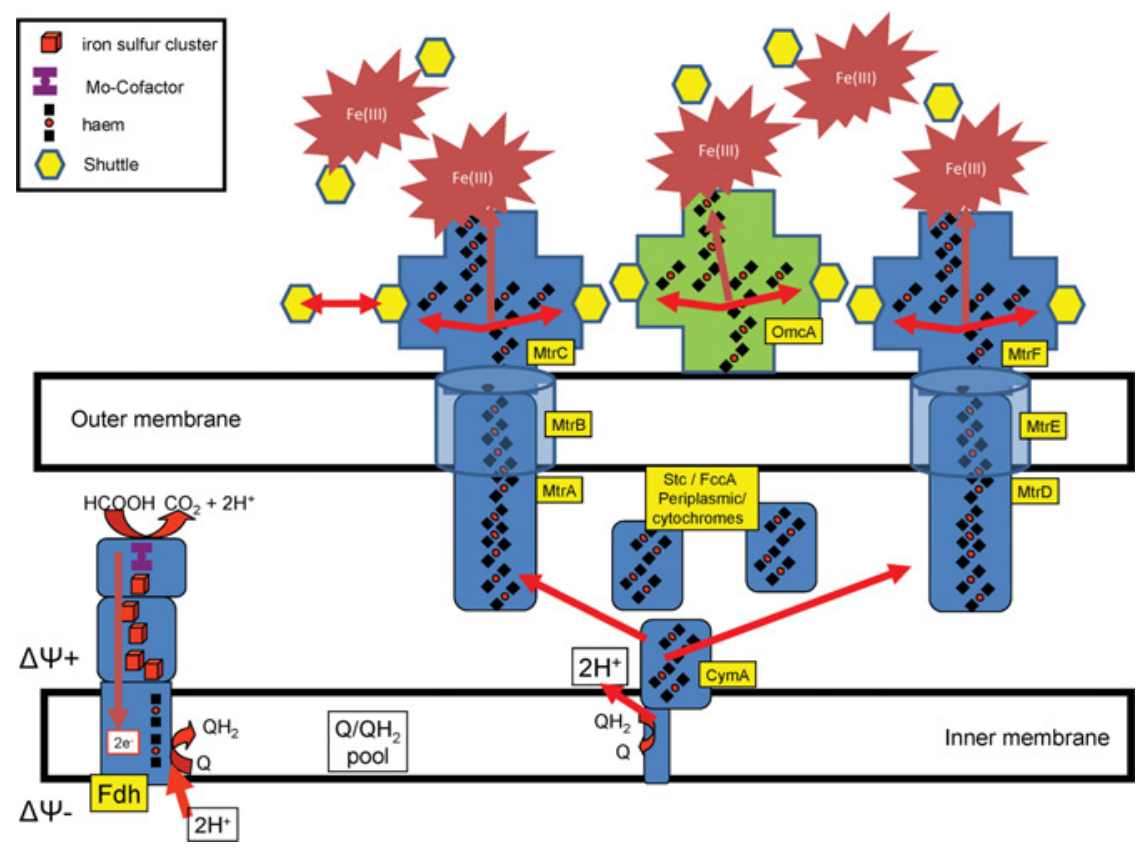

Figure 2 | The structure and multi-haem organization of MtrF

(A) Crystal structure of MtrF at $3.4 \AA$ coloured by domain: domain 1, red; domain 2, blue; domain 3, green; domain 4, purple. (B and C) Histidine ligands of the ten haems. Modified from Clarke, T.A., Edwards, M.J., Gates, A.J., Hall, A., White, G.F., Bradley, J., Reardon, C.L., Shi, L., Beliaev, A.S., Marshall, M.J. et al. (2011) Structure of a bacterial cell surface decaheme electron conduit. Proc. Natl. Acad. Sci. U.S.A. 108, 9384-9389 with permission. (C) 2011 the National Academy of Sciences of the United States of America.
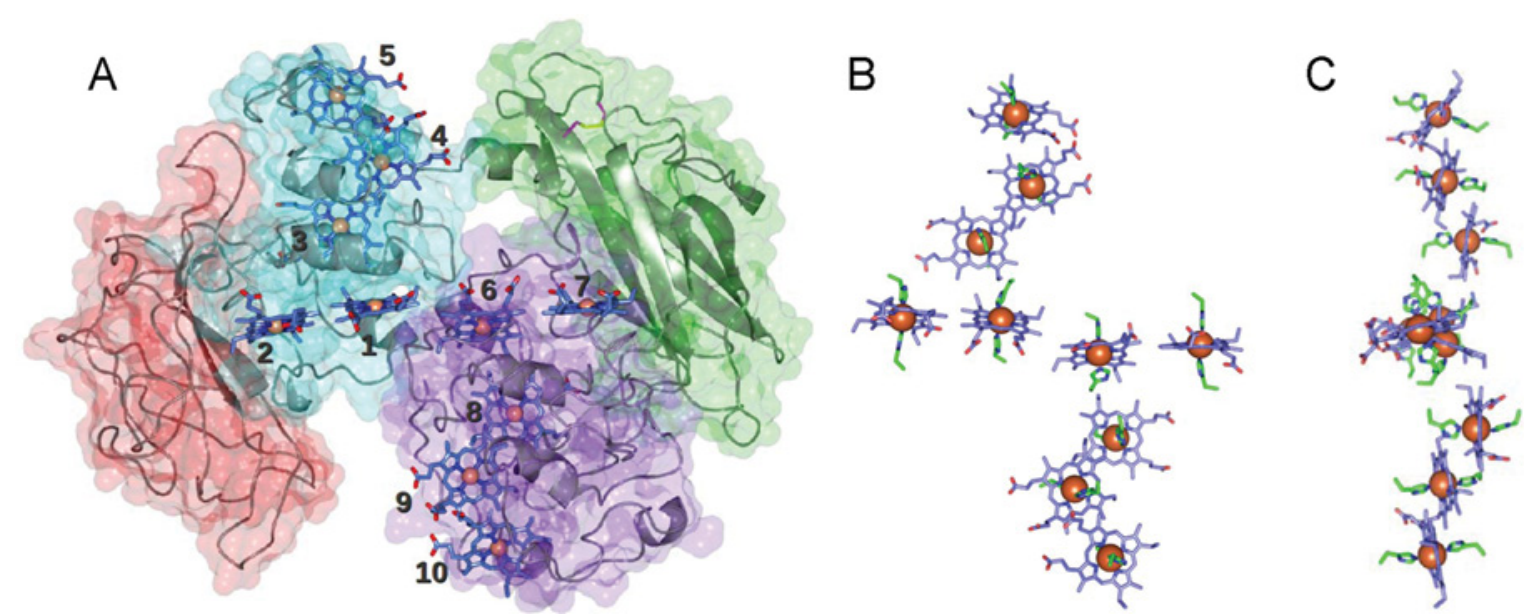

The first crystal structure of a Shewanella OMDC, MtrF, has recently emerged [8]. MtrF crystallizes as a monomer, and the structure reveals that the ten covalently bound haems are organized across four domains in a unique crossed conformation. A staggered $65 \AA(1 \AA=0.1 \mathrm{~nm})$ octahaem chain transects the length of the protein through two $\alpha$ helical domains and is bisected by a planar $45 \AA$ tetrahaem chain that connects two extended Greek key split $\beta$-barrel domains (Figure 2A). All adjacent haems have edge-to-edge distances of 4-6 $\AA$, which ensures rapid inter-haem electron transfer. The structure presents the possibility of a dualfunctional enzyme that can reduce insoluble minerals directly via solvent-exposed haems in the $\alpha$-helical domains, while also being able to reduce water-soluble electron shuttles, such as flavins, at the haem termini in the $\beta$-barrel domains [8].

The MtrF structure now provides a framework against which to compare the biochemical, spectral and potentiometric properties of other OMDCs using, where possible, data 
Figure 3 Clustering of $m t r$ genes and phylogenetic distribution of Shewanella outer-membrane decahaem cytochromes

(A) The mtr gene locus of S. oneidensis MR-1 and (B) phylogenetic analysis of MtrF, MtrC and OmcA. The genes, indicated by arrows, are shaded according to the predicted structure/localization where white arrows denote periplasmic or outer membrane-associated decahaem c-type cytochromes, grey arrows denote outer-membrane $\beta$-barrels, and black arrows indicate outer-membrane decahaem $\boldsymbol{c}$-type cytochromes. The predicted promotors are shown as bent arrows and terminators as hairpin loops. (B) Phylogenetic tree constructed with the ALIGNX program of Vector NTI (Invitrogen), based on the amino acid sequences of $19 \mathrm{MtrC}, 13 \mathrm{MtrF}$ and 14 OmcA homologues identified from the sequenced Shewanella strains. These included S. amazonensis (Sam), S. baltica OS155, OS185, OS196 and OS223 (0S155, OS185, OS196 and OS223), S. benthico (Sbe), S. frigimarino (Sfr), S. halifaxensis (Sha), S. loihica PV-4 (PV-4), S. oneidensis MR-1 (MR-1), S. pealeona (Spe), S. putrefociens CN-32, W3-18-1 and 200 (CN-32, W3 and 200), S. sedimins (Sse), Shewonello spp. ANA-3, MR-4 and MR-7 (ANA-3, MR-4 and MR-7), and S. woodyi (Swo). The numbers in parentheses after the homologue names represent their calculated evolutionary distances.
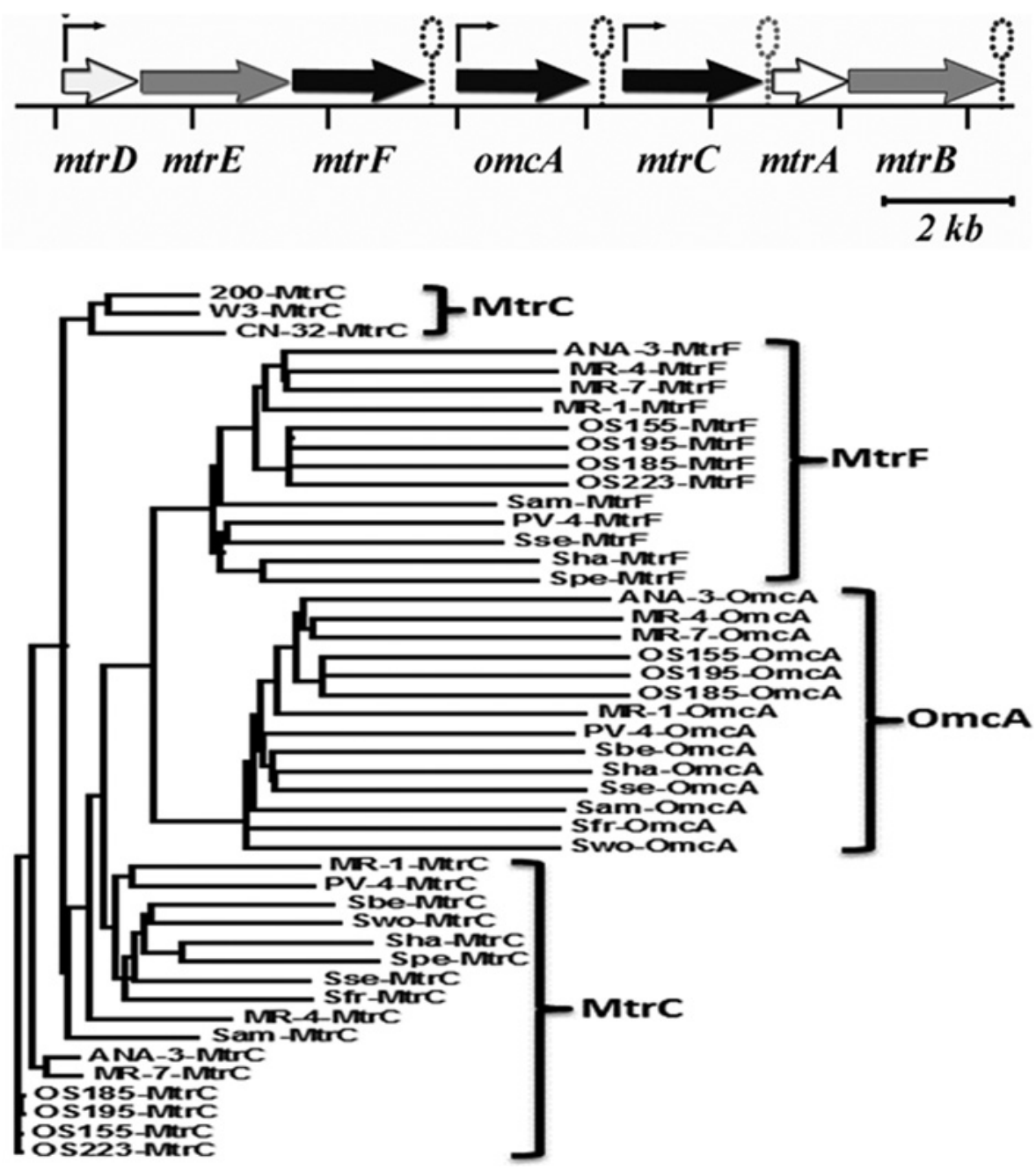

collected under common sets of experimental conditions. Such a comparison is described in the present paper through a consideration of the published properties of $\mathrm{MtrC}$ in the light of the MtrF structure. Where required, some new data on MtrC or MtrF are presented to test predictions that arise from the comparisons. MtrC has long been the paradigm member of the Shewenella OMDC superfamily, and so the comparison presented helps to illuminate the common and distinct properties of these two different clades of multi-haem cytochromes.

\section{Phylogenetic and primary structure analyses of MtrF and MtrC}

In S. oneidensis, the genes encoding MtrF and MtrC are co-located in a single gene cluster (Figure 3A). Sequence alignment shows that these two proteins display $30 \%$ identity, but the $m t r C$ and $m t r F$ genes appear to be differentially regulated, suggesting different physiological functions rather than functional redundancy. OmcA and MtrC are both synthesized at high levels during planktonic growth of $S$. oneidensis, but MtrF is not detectable under these growth 
Figure 4 | Alignment of the primary structures of MtrF and MtrC

Putative domains, based on the MtrF structure, are sequentially coloured red, blue, green and purple for domains I-IV to correlate with domain colouring in Figure 2. The italicized numbered histidine residues (highlighted in blue) provide the distal ligand to the haem bound by the $\mathrm{CX}_{2} \mathrm{CH}$ motif (highlighted in yellow) of the same number. The putative $\mathrm{LX}_{2} \mathrm{C}$ cleavage and lipid-binding site is highlighted in red and the cysteine residues of domain III C $\mathrm{X}_{8} \mathrm{C}$ disulfide are highlighted in green. The conserved Asp 361 is also highlighted in blue.

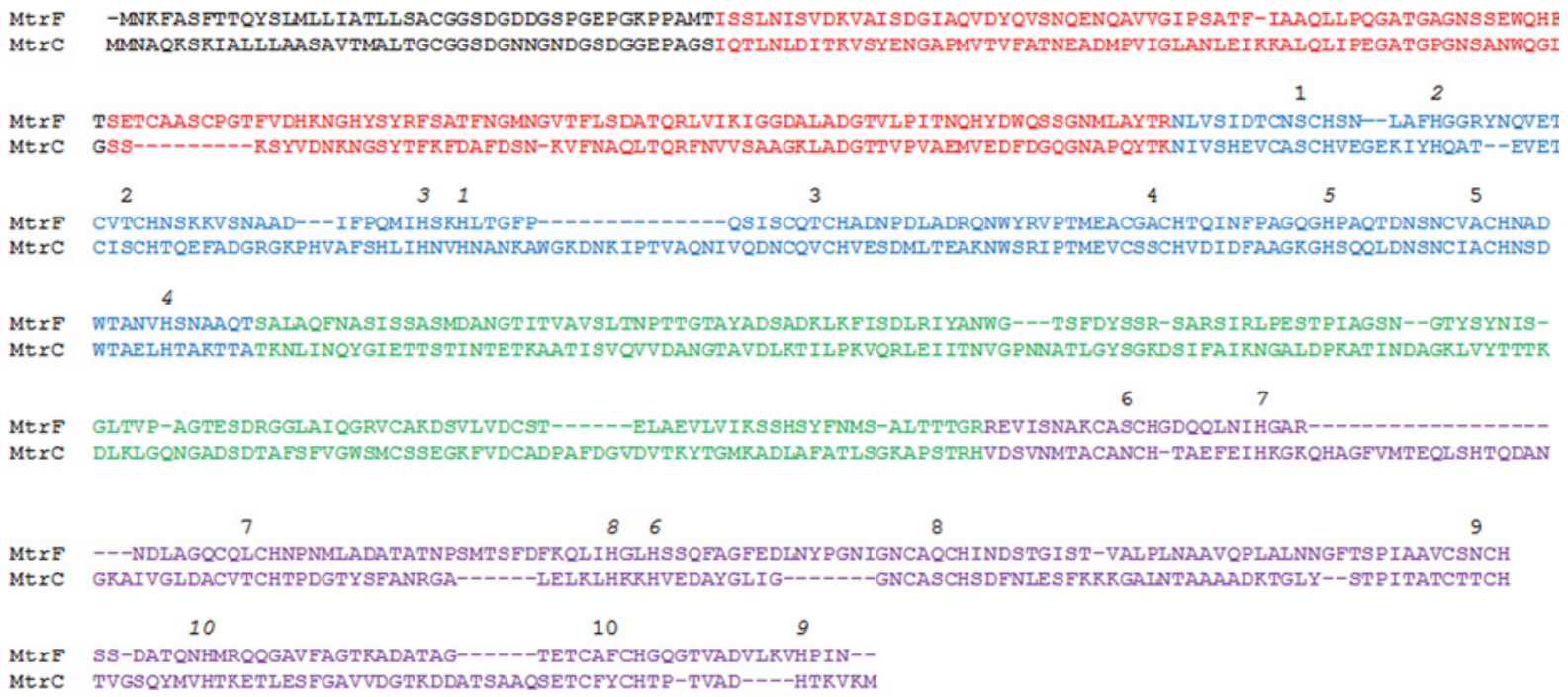

conditions. Previous work has instead shown that $m \operatorname{tr} F$ is expressed during biofilm growth [4]. A phylogenetic tree of the OMDC superfamily was constructed on the basis of the amino acid sequences of $19 \mathrm{MtrC}, 13 \mathrm{MtrF}$ and $14 \mathrm{OmcA}$ homologues identified from the $\sim 20$ sequenced Shewanella species and strains [9]. It was notable that MtrF homologues are clustered tightly together, but MtrC homologues are more divergent (Figure 3B). Comparative analysis of the primary structures of $S$. oneidensis $\mathrm{MtrC}$ and $\mathrm{MtrF}$ suggests that $\mathrm{MtrC}$ will fold into the four-domain configuration adopted by MtrF, in which the ten $\mathrm{CX}_{2} \mathrm{CH}$ haem-binding motifs are arranged in two $\sim 150$-amino-acid pentahaem domains (Figure 4). MtrC is a larger protein (671 amino acids) than $\mathrm{MtrF}$ (639 amino acids), and the bulk of this extra polypeptide is present as insertions in the domain I and II interface. In fact, much of the sequence identity between MtrC and MtrF is accounted for by 20 cysteine and 20 histidine residues involved in binding the ten haem cofactors. All ten $\mathrm{CX}_{2} \mathrm{CH}$ haem-binding motifs are in spatially similar positions in the polypeptide chain, suggesting that the overall organization of the ten haem groups in MtrC will be similar to that in MtrF and will therefore also display the haem-cross arrangement. In addition, ten conserved histidine residues that lie outside of the $\mathrm{CX}_{2} \mathrm{CH}$ motifs can also be aligned in the primary structures, suggesting that, like MtrF [8], all ten MtrC haems are expected to have hexa-co-ordinated iron sites with bishistidine axial ligation (Figures $2 \mathrm{~B}$ and $2 \mathrm{C}$ ).

\section{Probing the role of the non-haem-binding cysteine residues}

Analysis of the primary structures of MtrC and MtrF also reveal conserved cysteine residues that are not part of a

\section{Figure 5 | The surface disulfide of MtrC and MtrF}

(A) The presence of redox-dependent disulfide-dithiol transitions in MtrC. Samples were either analysed 'as isolated' (oxidized) or reduced by DTT and incubated with or without the thiol-probe (AMS). Samples were resolved by SDS/PAGE (8\% gels) and relative migration distances were visualized by haem staining. (B) Image of the disulfide in MtrF.

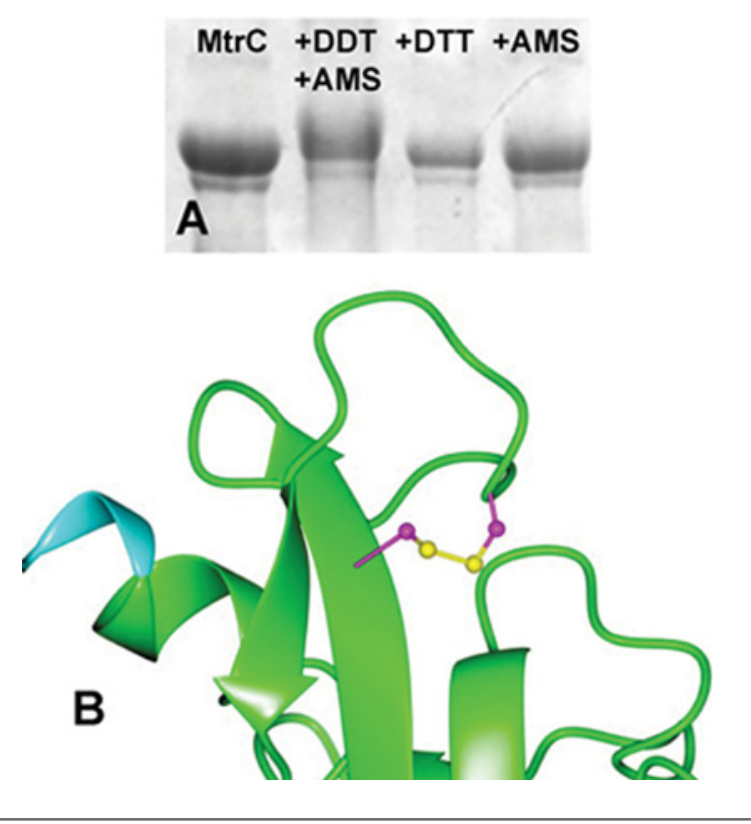

$\mathrm{CX}_{2} \mathrm{CH}$ haem-binding motif. The MtrF crystal structure revealed that two cysteine residues in a $\mathrm{CX}_{8} \mathrm{C}$ motif in domain III form a disulfide bond (Figure 5). The $\mathrm{CX}_{8} \mathrm{C}$ motif is conserved in MtrC (Figure 4). Towards the N-terminus, a single cysteine residue in $\mathrm{MtrF}$ and $\mathrm{MtrC}$ is conserved within 
Figure 6 | Comparison of visible spectropotentiometric properties of MtrC and MtrF

(A and B) Reduced and oxidized spectra of $\sim 4 \mu \mathrm{M} \operatorname{MtrC}(\mathbf{A})$ and $\operatorname{MtrF}(\mathbf{B})$ at pH 7. Continuous lines, oxidized; broken lines, reduced. (C) Mediated redox titration measured at $550 \mathrm{~nm}$ and performed as described in [14]. O, MtrF;
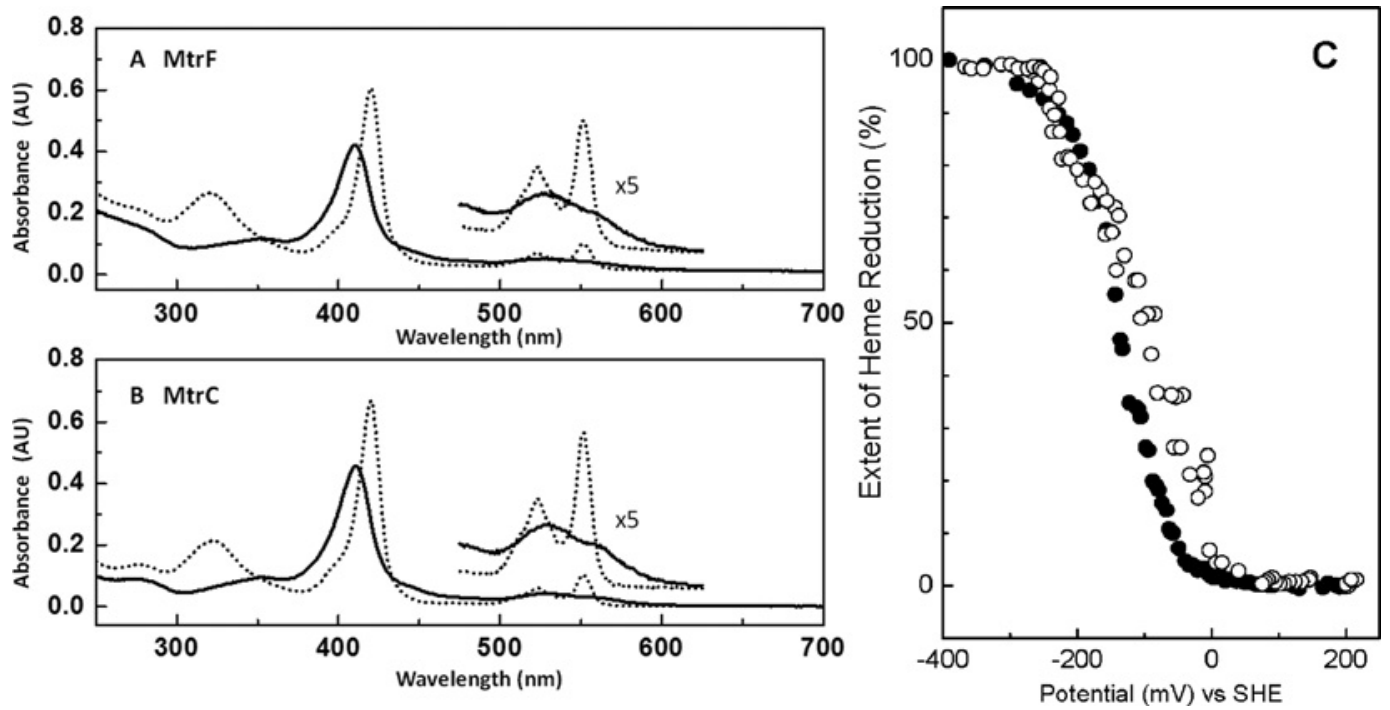

a putative Lipo-box $\left(\mathrm{LX}_{2} \mathrm{C}\right)$ motif and thus both proteins are likely to bind a lipid anchor (e.g. $N$-acyl-S-diacylglycerol) attachment following protein maturation. In MtrC, it has been demonstrated that this protein maturation involves translocation of the peptide to the extracellular face of the cell membrane via the TS2 (Type 2 secretion) system $[10,11]$. Non-acylated forms of MtrC accumulate in the extracellular medium since they are not able to bind effectively to the outer membrane. This accumulation is not as prevalent in strains deficient in functional TS2. We have confirmed that this is also the case for MtrF (results not shown).

The presence of conserved $\mathrm{CX}_{8} \mathrm{C}$ motifs in domain III of OMDC sequences (Figure 4) suggested that these proteins may also form structural disulfides, a prediction now validated by the MtrF crystal structure [8]. To explore this possibility for MtrC, in the absence of a crystal structure, we probed the proteins for AMS (4-acetamido-4'-maleimidylstilbene2,2'-disulfonic acid)-mediated mobility shifts on SDS/PAGE gels (Figure 5). AMS covalently labels free thiols only and so cysteine residues in a disulfide-bonded form are not labelled. The covalent attachment of AMS results in the addition of $\sim 500 \mathrm{Da}$ mass to each free thiol that causes a shift in protein mobility when resolved by non-reducing SDS/PAGE. MtrC migrated as a $\sim 75 \mathrm{kDa}$ haem-staining protein under three control conditions: (i) in the absence of the reductant DTT (dithiothreitol); (ii) in the absence of AMS; or (iii) in the presence of DTT, but in the absence of AMS (Figure 5). However, when reduced with DTT and coincubated with AMS, the migration of MtrC was retarded, indicative of an increased molecular mass due to the covalent attachment of the AMS molecular probe to cysteine thiol groups (Figure 5). These results demonstrate the presence of at least one intramolecular disulfide bond that can be reduced by DTT, which is likely to arise from the $\mathrm{CX}_{8} \mathrm{C}$ motif for which such a disulfide can be identified in the MtrF structure [8] (Figure 5).

\section{Comparison of the spectroscopic properties of MtrC and MtrF}

The UV-visible spectra of MtrC and MtrF are very similar (Figure 6). The air-oxidized spectra of both proteins display a haem Soret $(\gamma)$ absorbance peak centred at $410 \mathrm{~nm}$, a visible region peak at $531 \mathrm{~nm}$ and a shoulder at $\sim 560 \mathrm{~nm}$. These spectra remained unaltered upon further oxidation with excess potassium ferricyanide. On reduction with sodium dithionite, the Soret $(\gamma)$ peak shifts to $419 \mathrm{~nm}$, and clearly defined $\alpha$ - and $\beta$-peaks are observed at 552 and $523 \mathrm{~nm}$ respectively (Figure 6). The spectral features are indicative of $c$-type cytochromes, and no significant contribution arising from highspin haem (indicated by a weak absorbance band at $\sim 630 \mathrm{~nm}$ in the oxidized spectrum) was present in either protein.

The EPR spectra of oxidized MtrC and MtrF recorded under identical conditions confirm that all haems are lowspin (Figure 7A). No intense signal is present at $g \sim 6$ that would indicate a significant population of high-spin haem. This is consistent with the UV-visible spectra of both proteins presented above and also the absence of penta-coordinate haem in the MtrF structure (Figures 2B and 2C). A low-spin rhombic signal, LS1 $\left(g_{1,2,3}=2.97,2.27,1.5\right)$ is common to both cytochromes. Such a signal typically arises from low-spin ferric haems with bis-histidine ligation in which the planes of the bis-imidazole rings are approximately parallel. The presence of these signals is consistent with a significant proportion of the ten haems in each protein being co-ordinated in this way (Figure 2). For MtrF, spin integration shows that this signal accounts for $50-60 \%$ of the total haem, and six of the ten haems display this ligand 
Figure 7 | X-band EPR of MtrF and MtrC

(A) Continuous-wave X-band EPR (perpendicular mode) of MtrF and MtrC collected at pH 7.5. Spectra were recorded at $10 \mathrm{~K}$, with microwave frequency, $9.68 \mathrm{GHz}$; microwave power, $2 \mathrm{~mW}$; modulation amplitude, $0.1 \mathrm{mT}(10 \mathrm{G})(\mathrm{see}[8,14]$ for details). (B) Potential dependence of the LS2 signal intensity (percentage of maximum) for $\operatorname{MtrC}(\square)$ and $M \operatorname{MtF}(\Delta)$ measured at $g=2.86$. (C) Detail of the protein environment around the MtrF haem 10 showing Asp ${ }^{261}$.
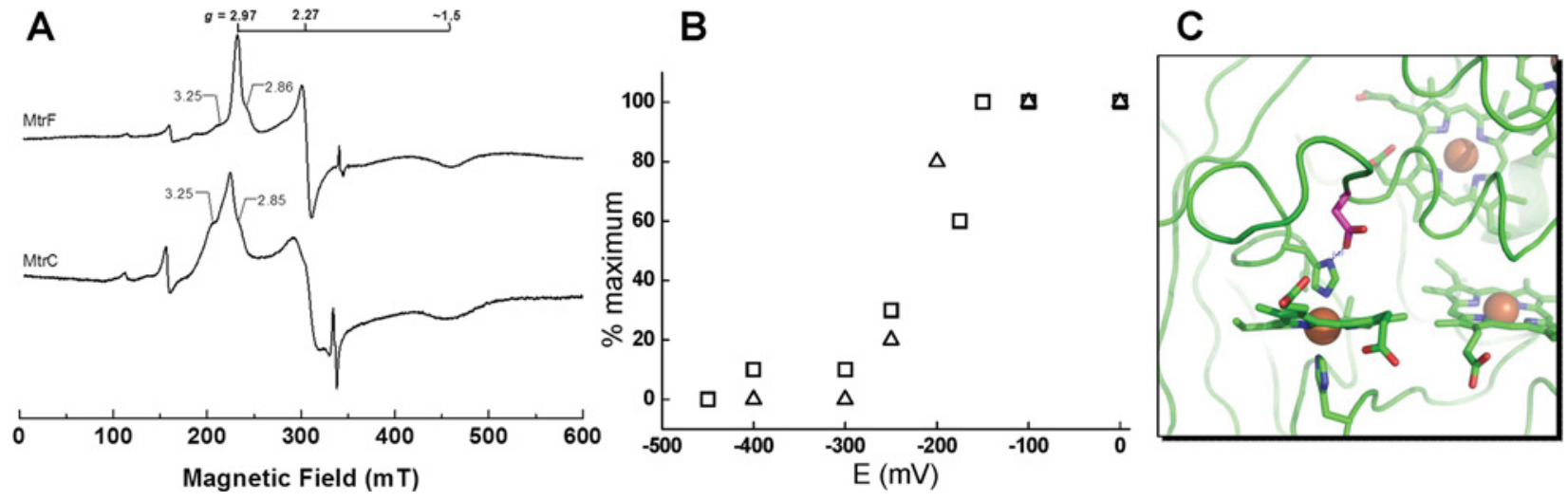

configuration in the crystal structure (Figures $2 \mathrm{~B}$ and $2 \mathrm{C}$ ). The EPR spectra of MtrC and MtrF also have in common a broad signal on the low field side of the $g_{1}$ feature of LS1 at $g \sim 3.15-3.25$ that was most intense in MtrC (relative to the intensity of the LS1 $g_{1}$ signal). These signals are characteristic of LGM (large $g_{\max }$ ) signals and arise from low-spin bishistidine-co-ordinated ferric haems in which the planes of the imidazole rings are near-perpendicular. The intensity of the LGM1 population in MtrC suggests that more haems may adopt this near-perpendicular co-ordination by histidine side chains compared with the three haems that display this geometry in MtrF. MtrC has another EPR signal in common with MtrF that is present as a shoulder on the intense LS1 peak at $g \sim 2.86$ (Figure 7A). This feature, which we term LS2, represents a second rhombic signal with $g_{1,2,3}$ $=2.86,2.31$ and 1.63 in MtrF that has greatly decreased rhombicity $\left(g_{1}-g_{3}=1.2\right)$ compared with LS1 $\left(g_{1}-g_{3}=\right.$ 1.48). Such lower rhombicity has been observed when a ferric haem imidazole ligand deprotonates to an imidazolate [12]. Histidine-histinate ligation tends to lower the potential of a haem compared with histidine-histidine ligation. Redox titration of the LS2 signal in both MtrC and MtrF reveal a similar potential dependence from which a midpoint reduction potential of $\sim-250 \mathrm{mV}$ can be determined for this haem population (Figure 7B). Increased solvent exposure may contribute to a haem titrating at lower potentials and so, on this basis, haem 10, which is a potential electron-input site into the protein, is a strong candidate (Figure 2A). Inspection of the environment around haem 10 in MtrF shows that the $\mathrm{N}_{\delta}$ of the proximal histidine ligand is in close proximity $(\sim 3 \AA)$ to the $\mathrm{Asp}^{361}$ carboxy group (Figure $\left.7 \mathrm{C}\right)$. This could lead to deprotonation of the histidine to give it imidazolate character, as seen for example on the proximal histidine ligand of cytochrome $c$ peroxidase [13]. This aspartate residue is also conserved in MtrC, suggesting that it is a common structural feature in these proteins.

\section{Comparison of the potentiometric properties of MtrC and MtrF}

To compare the redox potential distribution of the haems within MtrC and MtrF, mediated potentiometric titrations monitored by UV-visible spectroscopy were performed (Figure 6B). In each case, the redox state of the protein was followed over the course of each titration by monitoring the $\alpha$-peak absorbance that is present in the region $500-600 \mathrm{~nm}$. $\mathrm{UV}$-visible spectra were recorded at desired potentials over a solution potential range between +300 and $-450 \mathrm{mV}$ [compared with the SHE (standard hydrogen electrode)] and the normalized $\alpha$-peak absorbance ( $A_{552}$ in each case, compared with an isosbestic point at $A_{562}$ ) was plotted against solution potential (Figure 6B). Reduction of both MtrC and MtrF was observed below $\sim 0 \mathrm{mV}$, and the proteins were fully reduced at $-450 \mathrm{mV}$ (Figure 6B). This process was fully reversible and took place over a relatively large potential range spanning some $450 \mathrm{mV}$. The redox titration for a mono-haem $(n=1)$ cytochrome typically spans $\sim 90 \mathrm{mV}$. The broad redox potential range spanned by the haems in both MtrC and MtrF reflect the contribution of multiple haems with overlapping redox potentials that could not be adequately resolved given the resolution of this experimental technique, precluding the assignment of individual haem redox potentials.

To compare further the thermodynamic properties of MtrC and MtrF, protein films can be prepared on the surface of basal-plane graphite electrodes and the electrochemical response monitored using PFV (protein film voltammetry). In the absence of substrate, PFV measurements on adsorbed films yield stable signals each consisting of a pair of peaks (Figure 8). For both MtrC and MtrF, signals are unchanged upon electrode rotation (0-4000 rev./min) or following transfer of the protein-coated electrode into fresh buffer/electrolyte solution. As no signal was observed from the electrode in the absence of protein, the voltammetric 
Figure 8 Cyclic voltammograms of MtrC and MtrF

Each voltammogram illustrates the engineered baseline response-subtracted $\mathrm{MtrC}$ or $\mathrm{MtrF}$ response at $\mathrm{pH} 7$ and scan rate $30 \mathrm{mV} \cdot \mathrm{s}^{-1}$ (for further details, see $[8,14])$. Above and below each cyclic voltammogram, the direction of electron exchange between the electrode and protein is indicated.
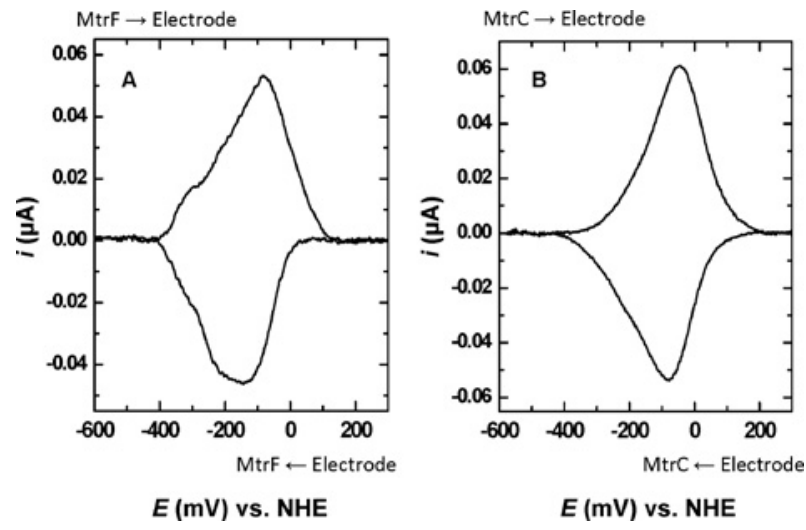

response can be attributed to direct redox transformation of the haem centres present within the relevant protein. The peak height $\left(I_{\mathrm{p}}\right)$ of the response corresponds linearly with scan rate $(v)$, indicating that the response is due to surface-adsorbed proteins on the electrode surface (results not shown). At $\mathrm{pH} 7.0$, integration of the $\mathrm{MtrC}$ and MtrF responses suggested an electroactive coverage $\left(\Gamma_{\mathrm{o}}\right)$ of $\sim 2 \mathrm{pmol} \cdot \mathrm{cm}^{-1}$. Facile electron transfer was observed between both MtrF and MtrC protein films and the basal graphite electrode, as demonstrated by the small separation of peaks $\left(\Delta E_{\mathrm{p}}\right)\left(\mathrm{MtrF}, \sim 60 \mathrm{mV}\right.$ at $30 \mathrm{mV} \cdot \mathrm{s}^{-1}$; MtrC, 32 $\mathrm{mV}$ at $\left.30 \mathrm{mV} \cdot \mathrm{s}^{-1}\right)$. At $\mathrm{pH} 7.0$, the stoichiometric reversible reduction and oxidation of $\mathrm{MtrF}$ and MtrC haems occurs between $\sim+50 \mathrm{mV}$ and $-400 \mathrm{mV}$. The half-height width $(\delta)$ of the signals is $\sim 150-200 \mathrm{mV}$. This is much broader than that of independently $n=1$ or $n=2$ haems (86 or $43 \mathrm{mV}$ respectively) and thus reflects that a number of haems contribute to these composite signals. Rigorous analysis of interfacial electron transfer kinetics is therefore precluded by the overlapping contributions to the peaks. However, fitting the scan-rate-dependence of the apparent peak potential using a Butler-Volmer description of a single adsorbed redox centre gives an approximation of the rate of interfacial electron transfer. For MtrC and MtrF, a rate of $\sim 200 \mathrm{~s}^{-1}$ has been estimated at the peak potential, which reflects an inherent capacity of these proteins to rapidly pass electrons to extracellular solid substrates, in this case represented by the electrode $[3,8,14]$.

Both MtrC and MtrF reduced Fe(III) chelates with rates that decrease in the order Fe-EDTA $>$ Fe-NTA $>$ Fe-citrate. The rates with $\mathrm{Fe}(\mathrm{III})$-EDTA are comparable with secondorder rate constants of $0.8 \mu \mathrm{M}^{-1} \cdot \mathrm{s}^{-1}$ and $2.6 \mu \mathrm{M}^{-1} \cdot \mathrm{s}^{-1}$ for $\mathrm{MtrC}$ and $\mathrm{MtrF}$ respectively $[8,15]$. The reactions between MtrC or MtrF and an Fe(III) chelate is, in some cases, polyphasic. In the light of the crystal structure of MtrF, this could be potentially attributed to reactions at different haem termini in the proteins. Both MtrC and MtrF are also capable of rapidly passing electrons to flavins, consistent with the dual role of direct electron transfer to $\mathrm{Fe}$ (III) oxides and reduction via flavin shuttles [8,15-17].

\section{Concluding remarks: coupling the $\mathrm{MtrC}$ and MtrF activity to protonmotive force generation across the inner membrane}

The OMDCs MtrC and MtrF are believed to be the terminal contact point of the multihaem electron-conducting wire connecting the bacterial inner membrane to the insoluble terminal electron-accepting minerals of $\mathrm{Fe}(\mathrm{III})$ and $\mathrm{Mn}(\mathrm{IV})$ (Figure 1). The structural, spectroscopic and voltammetric characterization of the components of these multihaem $c$ type cytochromes has suggested that, in both cases, the ten haems are organized as bis-histidine-co-ordinated lowspin haem-crosses, as exemplified by MtrF, that operate at relatively low redox potentials $(+50$ to $-450 \mathrm{mV}$ compared with the SHE). The low redox potentials of the Fe(III) respiration system have bioenergetic consequences that limit the number of protonmotive coupling sites that can be associated with it. Depending on growth conditions, electrons could enter the $\mathrm{MQH}_{2}$ (reduced menaquinone) pool via the activity of primary dehydrogenases, such as the protonpumping NADH dehydrogenase, or electrogenic formate dehydrogenase or hydrogenase. The redox potential of the $\mathrm{NAD}^{+}-\mathrm{NADH}, \mathrm{CO}_{2}-\mathrm{HCOO}^{-}$or $2 \mathrm{H}^{+}-\mathrm{H}_{2}$ couples in the cell will lie in the vicinity of -300 to $-400 \mathrm{mV}$ and that of MQ (oxidized menaquinone)- $\mathrm{MQH}_{2}$ will be approximately -50 to $-100 \mathrm{mV}$. This thermodynamic energy gap $(\sim 300 \mathrm{mV})$ is sufficient to allow for generation of $\Delta p(\sim 200 \mathrm{mV})$ through coupling electron transport from donor to acceptor to either proton translocation via NADH dehydrogenase and/or an electrogenic redox loop (involving formate dehydrogenase or hydrogenase). However, there is not a sufficient thermodynamic driving force available to facilitate electron transfer from the quinol pool through the periplasmic and outer membrane low-redox-potential haem pool of CymA, Stc, MtrA, OmcA and MtrC in a protonmotive manner. Mechanistically, electrons need to be drawn through this system by a strong oxidant [for example, an $\mathrm{Fe}(\mathrm{III})$ mineral oxide]. There is no $\Delta p$ coupling site in this part of the electron-transport process, thus, no matter how oxidizing the Fe(III) species that terminates the electrontransport chain at the outside of the cell, the free energy in the $\mathrm{MQH}_{2}-\mathrm{Fe}$ (III) couple will be dissipated. Thus Fe(III) respiration is constrained to only be coupled to $\Delta p$ generation at the level of electron input into the MQ pool. The close interaction between all of the haems in the MtrF structure suggests that electron transfer through the haem wires will be rapid and this may enable the system to use the extracellular redox sink as a means of rapidly recycling the menaquinone pool. 


\section{Funding}

This research was supported by the Biotechnology and Biological Sciences Research Council and EMSL (Environmental Molecular Sciences Laboratory) Scientific Grand Challenge project at the W.R. Wiley EMSL, a national scientific user facility sponsored by the U.S. Department of Energy, Office of Biological and Environmental Research programme located at Pacific Northwest National Laboratory. The Pacific Northwest National Laboratory is operated for the Department of Energy by Battelle. D.J.R. is a Royal Society Wolfson Foundation Merit Award holder.

\section{References}

1 Shi, L., Squier, T.C., Zachara, J.M. and Fredrickson, J.K. (2007) Respiration of metal (hydr)oxides by Shewanello and Geobocter: a key role for multihaem c-type cytochromes. Mol. Microbiol. 65, 12-20

2 Reardon, C.L., Dohnalkova, A.C., Nachimuthu, P., Kennedy, D.W. Saffarini, D.A., Arey, B.W., Shi, L., Wang, Z., Moore, D., Mclean, J.S. et al. (2009) Role of outer-membrane cytochromes MtrC and OmcA in the biomineralization of ferrihydrite by shewonella oneidensis MR-1. Geobiology 8, 56-68

3 Hartshorne, R.S., Reardon, C.L., Ross, D., Nuester, J., Clarke, T.A., Gates, A.J., Mills, P.C., Fredrickson, J.K., Zachara, J.M., Shi, L. et al. (2009) Characterization of an electron conduit between bacteria and the extracellular environment. Proc. Natl. Acad. Sci. U.S.A. 106, 22169-22174

4 McLean, J.S., Pinchuk, G.E., Geydebrekht, O.V., Bilskis, C.L., Zakrajsek, B.A. Hill, E.A., Saffarini, D.A., Romine, M.F., Gorby, Y.A., Fredrickson, J.K. and Beliaev, A.S. (2008) Oxygen-dependent autoaggregation in Shewanello oneidensis MR-1. Env. Microbiol. 10, 1861-1876

5 Shi, L., Chen, B., Wang, Z., Elias, D.A., Mayer, M.U., Gorby, Y.A., Ni, S., Lower, B.H., Kennedy, D.W., Wunschel, D.S. et al. (2006) Isolation of a high-affinity functional protein complex between OmcA and MtrC: two outer membrane decahaem c-type cytochromes of Shewanello oneidensis MR-1. J. Bacteriol. 188, 4705-4714

6 Coursolle, D., Baron, D.B., Bond, D.R. and Gralnick, J.A. (2010) The Mtr respiratory pathway is essential for reducing flavins and electrodes in Shewanello oneidensis. J. Bacteriol. 192, 467-474

7 Coursolle, D. and Gralnick, J.A. (2011) Modularity of the Mtr respiratory pathway of Shewonello oneidensis strain MR-1. Mol. Microbiol. 77, 995-1008
8 Clarke, T.A., Edwards, M.J., Gates, A.J., Hall, A., White, G.F., Bradley, J., Reardon, C.L., Shi, L., Beliaev, A.S., Marshall, M.J. et al. (2011) Structure of a bacterial cell surface decaheme electron conduit. Proc. Natl. Acad. Sci. U.S.A. 108, 9384-9389

9 Fredrickson, J.K., Romine, M.F., Beliaev, A.S., Auchtung, J.M., Driscoll, M.E., Gardner, T.S., Nealson, K.H., Osterman, A.L., Pinchuk, G., Reed, J.L. et al. (2008) Towards environmental systems biology of Shewanella. Nat. Rev. Microbiol. 6, 592-603

10 Shi, L., Deng, S., Marshall, M.J., Wang, Z., Kennedy, D.W., Dohnalkova, A.C., Mottaz, H.M., Hill, E.A., Gorby, Y.A., Beliaev, A.S. et al. (2008) Direct involvement of type II secretion system in extracellular translocation of Shewonello oneidensis outer membrane cytochromes MtrC and OmcA. J. Bacteriol. 190, 5512-5516

11 Donald, J.W., Hicks, M.G., Richardson, D.J. and Palmer, T. (2008) The c-type cytochrome OmcA localizes to the outer membrane upon heterologous expression in Escherichio coli. J. Bacteriol. 190, 5127-5131

12 Gadsby, P.M.A. and Thomson, A.J. (1990) A theoretical model of the intensity of near-infrared porphyrin-to-iron charge-transfer transitions in low spin iron(III) hemoproteins: a correlation between the intensity of the magnetic circular dichroism bands and the rhombic distortion parameter of iron. J. Chem. Soc. Dalton Trans., 1921-1928

13 Goodin, D.B. and McRee, D.E. (1993) The Asp-His-Fe triad of cytochrome c peroxidase controls the reduction potential, electronic structure, and coupling of the tryptophan free radical to the haem. Biochemistry $\mathbf{3 2}$, 3313-3324

14 Hartshorne, R.S., Jepson, B.N., Clarke, T.A., Field, S.J., Fredrickson, J., Zachara, J., Shi, L., Butt, J.N. and Richardson, D.J. (2007) Characterization of Shewanella oneidensis MtrC: a cell-surface decahaem cytochrome involved in respiratory electron transport to extracellular electron acceptors. J. Biol. Inorg. Chem. 12, 1083-1094

15 Wang, Z., Liu, C., Wang, X., Marshall, M.J., Zachara, J.M., Rosso, K.M., Dupuis, M., Fredrickson, J.K., Heald, S. and Shi, L. (2008) Kinetics of reduction of Fe(III) complexes by outer membrane cytochromes MtrC and OmcA of Shewanello oneidensis MR-1. Appl. Environ. Microbiol. 74, 6746-6755

16 Ross, D.E., Brantley, S.L. and Tien, M. (2009) Kinetic characterization of OmcA and MtrC, terminal reductases involved in respiratory electron transfer for dissimilatory iron reduction in Shewanello oneidensis MR-1. Appl. Environ. Microbiol. 75, 5218-5226

17 Brutinel, E.D. and Gralnick, J.A. (2012) Shuttling happens: soluble flavin mediators of extracellular electron transfer in Shewonella. Appl. Microbiol. Biotechnol. 93, 41-48

Received 20 January 2012

doi:10.1042/BST20120018 